\title{
La alameda: Un estudio de la producción del espacio en Hatillo 8
}

\author{
David Araya Díaz
}

Invitado nacional

Profesional Independiente

darayad91@gmail.com

Recibido: 22 de mayo del 2017

Aceptado: 13 de noviembre del 2017

\section{David Araya Díaz}

Licenciado en Arquitectura por la Universidad de Costa Rica. Se desempeña como profesional independiente.

\section{Resumen}

El presente artículo nace del trabajo final de graduación del autor, en el cual se estudia un sector habitacional de la periferia del centro de San José, conocido como Hatillo 8, como caso paradigmático para comprender algunos elementos arquitectónicos y urbanos característicos de la estructura urbana en Costa Rica. Se explica brevemente el proceso metodológico cualitativo y algunos apuntes teóricos sobre la producción del espacio, las apropiaciones y la propiedad. Posteriormente, se desarrolla la descripción del proceso de producción de la alameda, como ejemplo entre las caracterizaciones realizadas en el trabajo de graduación. Así, el texto muestra que existen relaciones de poder desiguales que determinan el espacio, las cuales son claramente observables a partir del estudio de Hatillo 8.

Palabras clave: alameda; apropiación del espacio; propiedad; legislación urbana; producción del espacio; Hatillo.

\section{The "Alameda": A Study on the Production of Space in Hatillo 8}

\begin{abstract}
This paper is based on the final graduation project of the author. The research studies a neighborhood located near San José downtown, known as Hatillo 8, as a paradigmatic case to understand some architectural and urban elements characteristic of the urban structure in Costa Rica. The text briefly explains the qualitative methodological process and some theoretical statements on the production of space, appropriations and property. Then, it develops the description of the process of production of the "alameda", as an example of the characterizations made in the graduation work. Finally, the paper shows the unequal power relations that determines space, through the study of Hatillo 8.
\end{abstract}

Keywords: pedestrian street; appropriations of space; property; urban legislation; production of space; Hatillo. 


\section{Introducción}

E

n medio de las múltiples y diversas relaciones de poder en los ámbitos político, social y económico que producen los elementos arquitectónicos en el espacio, las personas que poseen una formación universitaria como profesionales en la construcción, la planificación urbana y el diseño arquitectónico únicamente representan un pequeño actor más que se suma dentro de estas múltiples y variables disputas por el espacio.

De lo anterior se entiende la relevancia que aún tienen las palabras de Lefebvre: "Los urbanistas parecen ignorar o desconocer que ellos mismos forman parte de las relaciones de producción que acatan las órdenes. Creen dominar el espacio y únicamente ejecutan" (1972, p. 156). Preocupado por esta afirmación, nace el trabajo final de graduación del autor para alcanzar el grado de licenciatura en arquitectura (Araya, 2016); dicho trabajo es base para este artículo, el cual pretende aportar a los debates y cuestionamientos en torno a los temas que se tratarán a continuación.

El artículo inicia en el siguiente apartado con una breve presentación de Hatillo 8 como caso de estudio. Posteriormente, se realizan unos apuntes teóricos que se consideran representativos del marco teórico del trabajo de graduación mencionado. Luego, se desarrolla una descripción de la metodología utilizada durante la investigación, con lo cual se plantea la reflexión sobre la investigación cualitativa en arquitectura.

Posteriormente, se profundiza únicamente en lo necesario para comprender los resultados de uno de los varios procesos de producción que se desarrollaron durante la investigación. Para esto se seleccionó a la alameda, usualmente vinculada con los sectores populares del país. En estos apartados se ahondará en las implicaciones que conceptos como propiedad y jerarquía tienen para la producción del espacio, lo cual se evidencia en las Normas mínimas de diseño geométrico en urbanizaciones (INVU, 1979b), el Reglamento para,el control nacional de fraccionamiento $y$ urbanizaciones (INVU; 1973, 1982, 1983) y el Glosario de términos de urbanismo y construcción (INVU, 1984). Además, se incluye un apartado sobre algunas apropiaciones del espacio que evidencian disputas entre los mandatos oficiales y lo vivido. Finalmente, a modo de conclusión, se caracteriza la alameda como elemento urbano.

\section{Hatillo como caso paradigmático}

Se entiende a Hatillo como un caso de estudio representativo del urbanismo en Costa Rica, y a Hatillo 8 como un caso crítico y paradigmático en relación a la totalidad del distrito. Sobre estas categorías, Flyvbjerg define caso paradigmático como el que ejemplifica las características esenciales de un paradigma particular y el caso crítico como "un caso con importancia estratégica para el problema general" (2004, p. 46); en otras palabras, es el caso menos probable o más probable para demostrar una cuestión. Además, plantea que solo por medio de este tipo de casos será posible obtener información valiosa para una generalización posterior de los resultados, o para realmente comprender las dimensiones y límites del fenómeno que se estudia.

Figura 1. Hatillo 1976-1979. En gris Hatillo 8, construido en dicho periodo. Elaboración propia con base en Calvo, S. 1982.

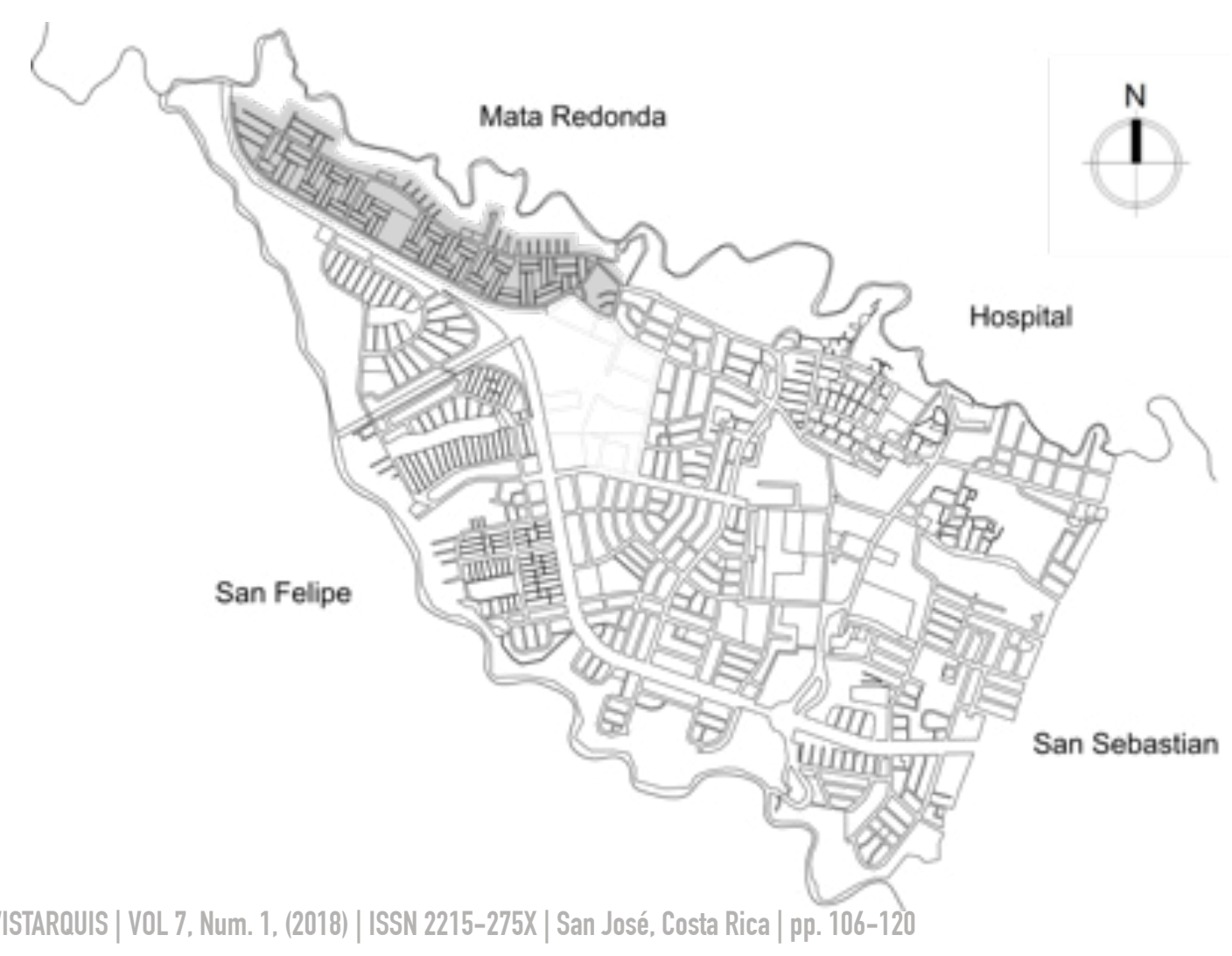


La construcción del proyecto de Hatillo dio inicio en 1954. Fue el más grande que jamás una institución estatal ha emprendido, y coincide con la creación por parte del Instituto Nacional de Vivienda y Urbanismo (INVU), ente encargado de las políticas de ordenamiento territorial y de promover programas habitacionales en el país, de leyes importantes para el urbanismo a nivel nacional, como el Reglamento para el control nacional de fraccionamiento y urbanizaciones (INVU, 1973; 1982; 1983) y las demás mencionadas anteriormente. Hatillo 8 (ver figura 2), por su parte, fue el último de los desarrollos del proyecto (finalizado a inicios de los años ochenta); es la etapa con mayor cantidad de viviendas y, al mismo tiempo, con mayor área construida promedio por cada vivienda, esto debido a que es el desarrollo con mayor cantidad de viviendas de dos niveles (vivienda "Tipo 600"), 1585 en total, de las cuales 1547 poseían una huella de tan solo $34,27 \mathrm{~m}^{2}$. Esta vivienda, que representa el $79 \%$ de las viviendas de Hatillo 8 , es de los tipos que ocupan los lotes más pequeños de entre todos los tipos de viviendas construidas en todo el distrito (INVU, 1979a).

En Hatillo 8, la disposición espacial de los elementos (entre ellos un diseño muy particular de alamedas) está claramente direccionada a incorporar en el menor espacio y con la menor inversión posible la mayor cantidad de propiedades. Por tanto, se puede afirmar que el diseño de Hatillo 8 logró obtener gran "eficiencia funcional" en el uso del suelo (ver figura 2); esto posiblemente se debe a que los gestores lo realizaron con mayor experiencia y con más conciencia de las implicaciones que podrían suceder a partir del diseño, ya que Hatillo no fue diseñado en su totalidad desde el inicio; cada etapa se diseñaba conforme se iba a desarrollar, proceso que cubre casi toda la segunda mitad del siglo XX.

Lo anterior permite comprender el proyecto de vivienda en cuestión como algo similar a un laboratorio de los planificadores para poner a prueba sus principios de diseño y la coincidencia ideológica de lo plasmado en Hatillo 8 con las normas publicadas por el INVU que se han mencionado anteriormente, las cuales se publicaron y reformaron tanto en las últimas etapas de construcción del proyecto de vivienda como posterior a él. Esto permite plantear que la caracterización que se desarrollará aquí de la alameda no solo aplica a las construidas en el caso de estudio de esta investigación, sino que puede ser un punto de partida para entender las vías peatonales en urbanizaciones en general a nivel nacional.

A continuación se anotan conceptos que fueron claves para lograr entender y vincular estas relaciones de poder plasmadas en el espacio, en el marco de una investigación en arquitectura.

Hatillo 8

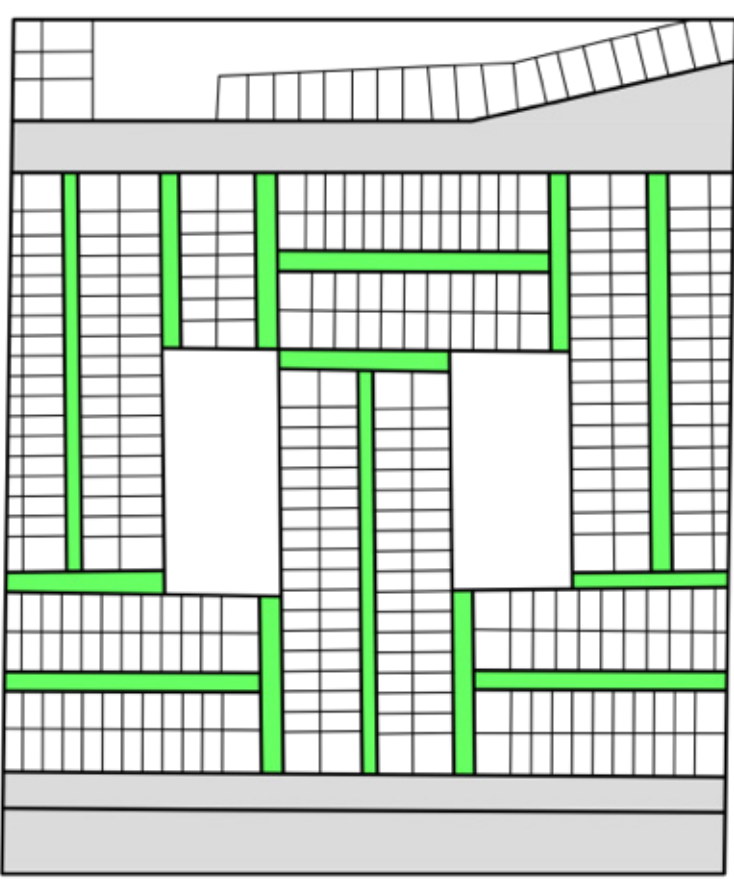

Hatillo 2

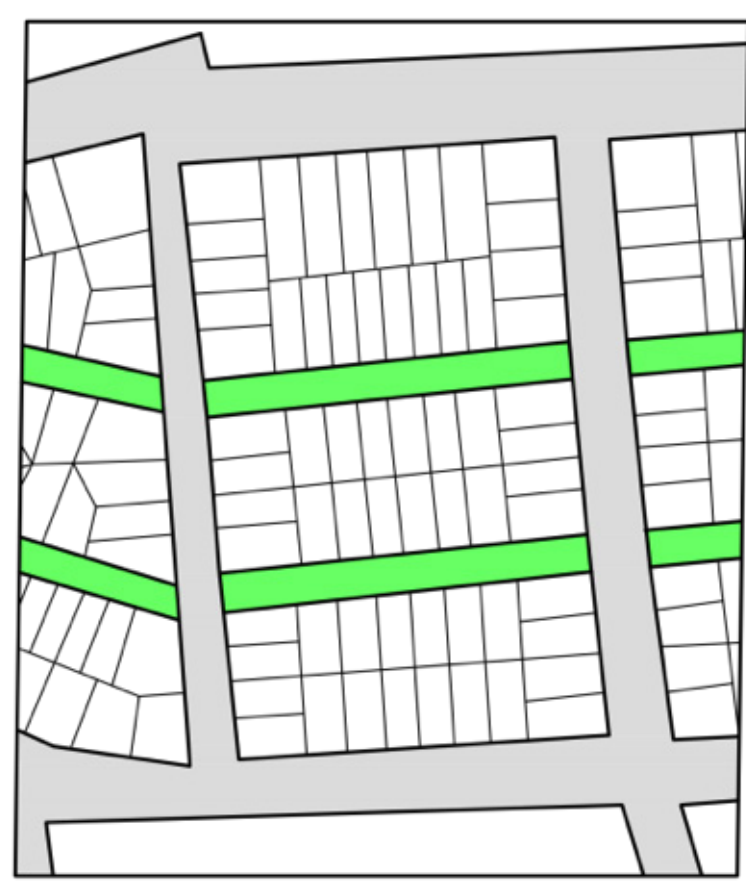

Apuntes teóricos sobre la producción del espacio

Sin que se pretenda ser exhaustivo en un marco teórico que podría extenderse muy ampliamente, en este momento solo se harán breves apuntes a partir de, principalmente, dos autores que se consideraron determinantes durante el desarrollo de la investigación: Henri Lefebvre y James C. Scott. 
Lefebvre argumenta que el espacio es un producto y como tal es producido. Esto conlleva implicaciones usualmente poco exploradas. En palabras del autor:

Si el espacio es un producto, nuestro conocimiento sobre él reproducirá y explicará ese proceso de producción. El interés y el «objeto» se desplazan desde las cosas en el espacio a la producción del espacio, (...) Tanto los productos parciales localizados en el espacio -las cosas- como los discursos sobre el espacio sirven únicamente de indicadores y de testimonios sobre ese proceso productivo (que comprende los procesos significantes, sin que se reduzca a ellos). (Lefebvre, 1974/2013, p. 96)

En este sentido, no solo conviene estudiar la historia del espacio, sino también adentrarse en la historia de los "testimonios" que encontramos en las representaciones del espacio, los discursos ideológicos y la práctica cotidiana en torno a él. Para desarrollar esta investigación histórica es necesario dar énfasis a los fundamentos detrás de las "conexiones, distorsiones, desplazamientos, interferencias y sus relaciones con la práctica espacial de las sociedades (o modos de producción)" (Lefebvre, 1974/2013, p. 101).

Es por esto que el presente texto se centra en la caracterización de un elemento urbano muy particular (la alameda), pero desde la relación que tiene con el "orden oficial" y el "orden vernacular". Estos conceptos, planteados por Scott, sirven para diferenciar las formas en que se entiende y apropia el espacio (Scott, 2012). El autor explica que la personalización local (de los modos de cultivar, las formas de apropiarse del espacio, los modos de nombrar y medir las cosas, etc.) realizada por comunidades antes del surgimiento de los estados-nación o por las que se han conservado al margen del poder estatal hasta hoy ("orden vernacular"), tiene un nivel de complejidad y sofisticación que solo puede ser comprendido por quienes habitan diariamente cada comunidad específica. Las instituciones estatales ("orden oficial"), en cambio, necesitan crear su propia legibilidad para comprender, regular y controlar todas estas variadas formas posibles de convivir (Scott, 1998).

La asignación de los nombres de los Hatillos a partir de números, abstracciones únicamente cuantitativas, es un claro ejemplo de esto. EI INVU, como ejecutor del orden oficial, asigna a cada etapa de los Hatillos un número para diferenciarlas (Hatillo 1, Hatillo 2, hasta el 8) y las tipologías de vivienda fueron identificadas también con números Esta forma de legibilidad simplificada es propia de las estructuras organizativas de tipo estatal y no necesariamente de las personas que habitan el lugar. En palabras de Scott:

La legibilidad implica un espectador cuyo lugar es central y cuya visión es sinóptica. Las simplificaciones estatales del tipo que hemos examinado son diseñadas para proveer a las autoridades de una visión esquemática de su sociedad, una visión que no se otorga a aquellos sin autoridad. (1998, p. 79 [traducción propia])

Continuando con lo demostrado por Scott en sus investigaciones, una de las principales herramientas que utilizan las instituciones estatales para lograr imponer sus formas de planificar el espacio es la propiedad privada. Con ella logran definir la jerarquía geométrica, social, económica y política que es útil para centralizar poder, recursos, etc. Este vínculo entre institución estatal y propiedad privada no es casual; en realidad "el mismo concepto de estado moderno presupone un régimen de propiedad legible, simplificado y uniforme, y por tanto manipulable desde el centro" (Scott, 1998, p. 35 [traducción propia]).

Lefebvre también identifica estos vínculos y evidencia el conflicto que existe entre la propiedad privada, que puede ser resumida geométricamente en impersonales catastros, y la apropiación, que remite a cambiantes y diversas formas de vivir el espacio (Lefebvre, 1974/2013, p. 389). Es decir, la propiedad privada y las representaciones de ella, realizadas por los planificadores desde las instituciones estatales, no comprenden el espacio desde lo vivido y la apropiación.

Por tanto, sería reduccionista pensar que la propiedad privada es un hecho dado de previo cuya configuración espacial no responde a relaciones de poder, al mismo tiempo, es necesario no comprender a las leyes, reglamentos, planes urbanos, representaciones técnicas y demás discursos oficiales como disposiciones neutras y necesarias para la organización social. En cambio, indica Lefebvre, se debe sospechar que detrás de reduccionismos como estos algún sector se ve beneficiado. En palabras de este autor: 


\begin{abstract}
El espacio es la morfología social; en ese sentido, el espacio es a lo «vivido» lo que al organismo vivo es a su propia forma, íntimamente ligada a las funciones y estructuras. Pensar el espacio a la manera de un «marco» o de una caja, en cuyo interior sólo puede ser introducido cualquier objeto siempre que sea más pequeño que el recipiente, imaginar que el contenedor sólo tiene como propósito preservar el contenido, todo eso constituye probablemente el error inicial. Pero ¿es error o ideología? Más bien lo último que lo primero. Pero entonces, ¿de quién se desprende esta ilusión ideológica? ¿A quién sirve? ¿Y por qué y cómo? (1974/2013, p. 149)
\end{abstract}

Además, antes de continuar, es importante explicar que en los términos de este documento se propone entender la propiedad como un "hecho social" que responde a multitud de relaciones sociales, económicas y políticas (Márquez, 2015) y que puede ser (además de privada o pública) cooperativa, comunal, de acceso abierto, entre muchos otros regímenes de propiedad posibles (Merino, 2014).

Por tanto, se propone entender a la propiedad privada como una "ilusión ideológica" 0 "ilegalidad fundante" (Nuñez, 2011) que históricamente se ha utilizado para controlar los modos de vida y de apropiación del espacio que no coinciden con el orden oficial, como se ha demostrado que sucedió durante el inicio del capitalismo en Europa (Federici, 2010), en la planificación de las ciudades en el mundo (Scott, 1998) y en procesos de colonización en América (Márquez, 2015) y Palestina (Hilal, Petti y Weizman, 2013), solo por mencionar algunos ejemplos.

Se podrá observar a lo largo del artículo que estos apuntes teóricos son necesarios para caracterizar a la alameda en tanto espacio producido, es decir, en sus múltiples y complejas relaciones y procesos de producción. Por ahora, se tomará un apartado para anotar cómo se incorporaron en el diseño metodológico los conceptos teóricos y las características particulares del caso a estudiar.

\title{
Un acercamiento a la investigación cualitativa en arquitectura
}

Los vínculos entre el alcance final del trabajo, el marco teórico-conceptual y el diseño metodológico llevaron a proponer una investigación cualitativa, que se enfoca desde dos actores distantes por su forma de acción y de concepción del espacio (el orden vernacular y el orden oficial), lo que provoca la necesidad de distintas herramientas para estudiar cada "orden". Por un lado, se tiene un estudio documental que, sin llegar a serlo completamente en sentido estricto, le debe mucho al análisis cualitativo del discurso, y por el otro, entrevistas semi-estructuradas, con cierto vínculo con el mapeo colectivo. Esta información se unifica por los conceptos derivados de la apropiación (Pol y Vidal, 2005), la propiedad y la producción del espacio, que son transversales en toda la investigación.

Se consideró que el enfoque cualitativo era el más apto para estudiar los conceptos de producción del espacio en esta investigación, debido a que se buscó comprender los principios de diseño de quienes planifican y quienes habitan desde sus intenciones, ideologías, discursos o acciones particulares. Por lo anterior en esta investigación se utilizaron pocas, pero relevantes, fuentes de información e informantes, ya que las muestras no se pretendieron seleccionar con la intención de "generalizar de manera probabilística los resultados a poblaciones más amplias" (Hernández, Fernández y Baptista, 2006, p. 9).

Por tanto, se tienen dos etapas iniciales que se aproximan a la comprensión de diversas relaciones que atraviesan y modifican los elementos arquitectónicos; luego, es gracias a la comprensión de estas relaciones que se proponen caracterizaciones de objetos concretos, no únicamente desde sus características físicas evidentes, sino como productos de procesos históricos, disputas, apropiaciones e imposiciones, obteniendo a partir de la última etapa resultados enfocados en lo arquitectónico y urbano, que es el ámbito principal de la investigación.

\section{Primera etapa: Estudio documental}

Esta etapa se centró en el estudio de documentos publicados por los actores con hegemonía y poder de decisión en cuanto al diseño, planificación y ejecución del 
1 Estas entrevistas se realizaron a lo largo del año 2015.

2 Por motivos de extensión del artículo no se pudo incluir mucha de esta información; para profundizar se puede consultar el trabajo de graduación completo del autor. Araya, 2016. proyecto. Por tanto, las fuentes de información están, en su mayoría, directamente relacionadas con el INVU. Dentro de estas fuentes de información se revisaron documentos oficiales del INVU entre 1973 y 1984 que se referían al proceso de diseño; documentos informativos de dicha institución, planos de los Hatillos -específicamente de Hatillo 8-, y, en especial, las siguientes publicaciones del INVU: las Normas mínimas de diseño geométrico en urbanizaciones (INVU, 1979b), el Reglamento para el control nacional de fraccionamientos y urbanizaciones (INVU, 1973; 1982; 1983) y el Glosario de términos de urbanismo y construcción (INVU, 1984a).

En esta etapa, se inició por la recolección de los documentos, categorizándolos en fichas técnicas. Luego, se realizó un estudio cualitativo de los documentos, identificando asociaciones y oposiciones, niveles de cultura, connotaciones cualitativas, lugares ideológicos, tipos de razonamiento y la relación entre locutor y destinatarios (Houtart, 2000). Finalmente, se analizó lo anterior para caracterizar los principios de diseño, incorporando herramientas como el estudio morfológico de planos (Kropf, 2009).

\section{Segunda etapa: Entrevistas}

Esta segunda etapa se centró en los y las habitantes de Hatillo 8; fue compuesta principalmente por entrevistas semi-estructuradas, que luego fueron analizadas. Se recibió el apoyo de 5 personas que participaron en las entrevistas con mayor profundidad, a la vez que se realizaron al menos 10 entrevistas informales más. Como se ha mencionado, con esta muestra se buscaron anécdotas de apropiaciones que fueran críticas o paradigmáticas en algún sentido, pero no interesó realizar generalizaciones probabilísticas.

La primera fase de esta etapa consistió en recolectar las memorias. El método fue organizar entrevistas semi-estructuradas individuales o en grupo ${ }^{1}$; se utilizaron mapas, planos y materiales de dibujo que permitieron aplicar dinámicas semejantes al mapeo colectivo (Ares y Rister, 2013). En cuanto a las entrevistas más informales, abundan conversaciones esporádicas con personas en la vía pública o comercios, incluyendo un pequeño taller con un grupo de niños y niñas durante una visita a la escuela Jorge Debravo, de Hatillo 8. La información recopilada en estos casos ayudó a direccionar el guión para las demás entrevistas.

En general, las ideas comunes en las entrevistas y talleres informales fueron reafirmadas por las informantes principales, y con estas últimas se conversó sobre sus vidas e historia personal para que cuando la conversación naturalmente lo provocaba o cuando se motivaba con alguna pregunta planeada anteriormente, se pudiese profundizar en las anécdotas de apropiaciones espaciales. Después de cada taller y entrevista se realizó un resumen de cada una, a la vez que se identificaba información relevante para ir agrupando ideas comunes o disímiles entre los informantes. Así se categorizaron y caracterizaron eventos, comportamientos o atribuciones simbólicas que las personas le hicieron a los espacios y momentos vividos. ${ }^{2}$

\section{Tercera Etapa: Caracterización de elementos}

En la última etapa se realizó la contraposición de los estudios de las fases anteriores, una vez se tuvieron los datos ya categorizados, codificados y definidos para su comparación. Se identificaron los elementos o espacios de la estructura urbana más relevantes para categorizarlos y caracterizarlos mediante el ensayo y las representaciones gráficas. De esta forma se amalgamaron las conclusiones de todas las fases anteriores y se describieron los resultados sintetizados en cuadros comparativos (Tonon, 2011).

A continuación se desarrollarán algunos de los datos históricos, hallazgos, argumentos y análisis necesarios para comprender uno de los elementos que se caracterizaron en los resultados de la investigación: la alameda. 


\section{La alameda: producto residual en disputa}

Se propone que para comprender la alameda es necesario entender cómo la propiedad y la jerarquía han ordenado el espacio; para esto, es necesaria la observación desde el marco ideológico hegemónico en la política nacional hasta las normas asignadas directamente a la regularización y disposición de los elementos urbanos. Luego, se muestra que siempre han existido apropiaciones opuestas a los mandatos oficiales y se ejemplifica con anécdotas específicas. A continuación desarrollamos estas ideas.

\section{Sobre la propiedad y la jerarquía en Costa Rica}

Siguiendo lo planteado por Manuel Antonio Solís (1992), en Costa Rica básicamente existen dos ejes políticos que a partir de los liberales en el siglo XIX se han repetido y utilizado en periodos de crisis o transición, que son: 1) la eficiencia en la producción a partir de la propiedad privada y 2) la estabilidad y equilibrio social partiendo del supuesto de que en Costa Rica los conflictos entre clases sociales son innecesarios.

Lo primero tiene que ver con el énfasis dado a lo económico como solución de todos los males sociales; la productividad es el principal objetivo y lo que las instituciones estatales deben hacer es ayudar a que los más pobres sean más productivos. Esta gran defensa de la pequeña propiedad familiar es lo que justifica la intervención estatal y la creación de proyectos de vivienda entre 1954 y 1982. No se realizan por equidad, su razón de ser es: "Ayudar a los más pobres a ser más productivos" (Solís, 1992, p. 25).

La propiedad privada ha sido, para los sectores que ostentan el poder en el país, "fuente de autoridad y de virtudes superiores (responsabilidad, capacidad administrativa, autovalía)" (Solís., 1992, p. 327). Por tanto, las nacionalizaciones y ampliación de las instituciones estatales durante la segunda mitad del siglo XX se entienden como necesarias para resolver un conflicto entre burguesías en busca de hegemonía (Esquivel y Solís, 1980), a partir de lo cual se deduce que nunca ha existido un planteamiento contrario a la propiedad privada como tal.

Además, no se intentan eliminar las diferencias entre las clases, ya que se parte de que dicha diferencia es natural e invariable. Alberto Martén y José Figueres Ferrer vieron en la sociedad la lucha por la supervivencia que veían en la naturaleza. La diferencia de clases para ellos tiene razones biológicas intrínsecas a la especie humana. Las jerarquías sociales nunca son cuestionadas estructuralmente (Solís, 1992).

\section{La propiedad como criterio espacial}

Siguiendo la interpretación histórica que se acaba de plantear, no sorprende que el concepto de propiedad privada sea un criterio muy importante en todos los textos estudiados. Antes de incluir criterios físico-ambientales, socio-culturales o de cualquier tipo, se parte de que la propiedad privada existe y se planifica desde ella. Así, los reglamentos la legitiman y, en alguna, medida la regulan.

La primera implicación espacial de esto es el lote, parcela o finca (las definiciones de cada uno de ellos son muy similares) ${ }^{3}$. La propiedad privada fragmenta el espacio ya que es necesario delimitarla, una vez fragmentado es necesario tener acceso a cada lote: "Las parcelas tendrán acceso directo a vía pública. El sistema vial de las urbanizaciones tendrá acceso adecuado al preexistente en el área o sector." (INVU, 1973, p. 10)

De lo anterior se podría deducir que la vía pública tiene como principal función, simplemente, acceder a la propiedad. Incluso, en muchos reglamentos se utiliza como sinónimo de vía pública el concepto de "derecho de vía"; esto hace alusión a la

3 "Parcela: Es la unidad catastral representada por una porción de terreno, que constituye una completa unidad física, y que se encuentra delimitada por una línea que, sin interrupción, regresa a su punto de origen". INVU, 1984, p. 71. posibilidad estrictamente de transitar, de circular, y no de permanencia o recreación, como se muestra en la siguiente cita de las Normas mínimas de diseño geométrico en urbanizaciones:

La principal función de las fajas de terreno destinadas a calles y senderos es la de permitir la circulación de vehículos y de peatones. Su derecho de vía y el ancho de los elementos 
Figura 3. Secciones de vías. Extraída de Reglamento para el control nacional de fraccionamiento y urbanizaciones. INUV, 1983, p.15.
$4 \quad$ Entre las versiones de 1973, 1982 y 1983 del citado documento, solo el de 1983 posee imágenes que ilustren la información. Además, cabe aclarar que las versiones mencionadas son documentos publicados por la Imprenta Nacional que se encontraron en su versión impresa en las bibliotecas de la Universidad de Costa Rica, por lo que no corresponden a las versiones publicadas en el Diario Oficial la Gaceta.

$5 \quad$ Es necesario anotar que la evidencia en la legislación urbana de principios de diseños funcionales y jerárquicos no es exclusiva de Costa Rica, ya que los procesos de racionalización y homogenización de las pautas espaciales mediante leyes es una característica del periodo moderno en la arquitectura a nivel internacional. Harvey, 1990; Scott, 1998; Somer, 2007. como pavimentos, aceras y fajas verdes, dependen del volumen y tipo de tránsito que debe acomodarse. [...]

Las calles y senderos tienen otra función de suma importancia, ya que a lo largo de ellos se instalan normalmente las redes de cañería, cloacas, alcantarillado pluvial y electricidad. Con adecuada arborización, además contribuyen mucho al ornato urbano. (INVU, 1979b, p. 9)

Los textos estudiados ignoran totalmente el uso cotidiano que las personas dan a las calles como espacios de recreación e intercambio (futbol callejero, juegos infantiles, ferias del agricultor, etc.); usos que, como se pudo constatar, siempre han sido frecuentes en las calles de Hatillo. Además, como se ve en la cita anterior, la siguiente función en orden de importancia es la de circulación de servicios básicos. Es funcional que los servicios circulen por el "derecho de vía", porque de otra forma no sería posible que todas las propiedades tengan acceso a ellos. Entonces, se podría entender la lógica mostrada aquí, y que se repite en los demás reglamentos, de la siguiente forma: primero se fragmenta el espacio en propiedades, luego se permite el tránsito en una red vial para tener acceso a las propiedades, y después de esto se incorporan los servicios para otorgarle utilidad a las propiedades.

Esta serie de criterios para diseñar el espacio se reafirma en todos los textos estudiados y en las representaciones del espacio que utilizan. Entre estas últimas, son escasos los ejemplos en los cuales aparecen figuras de personas.
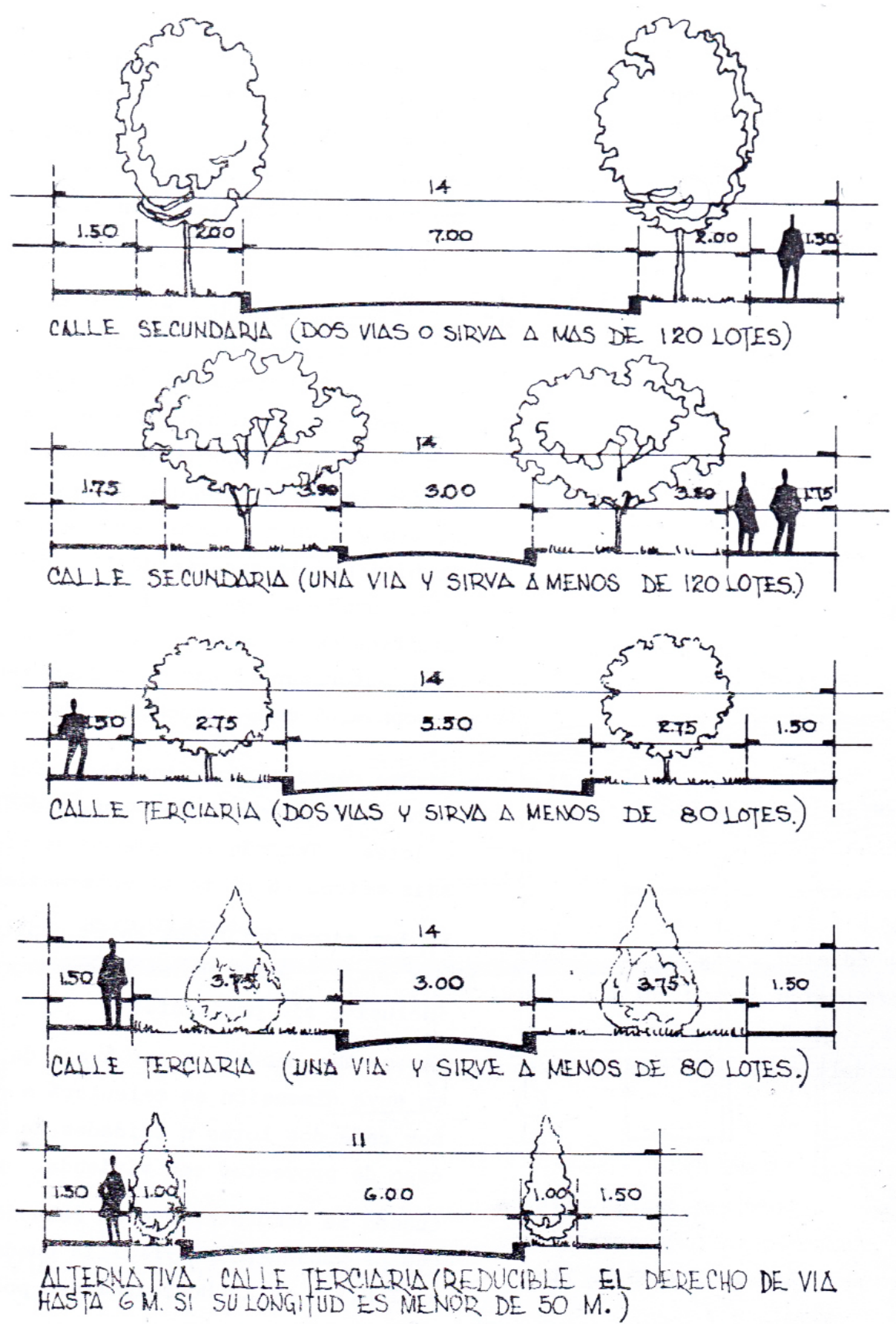

La figura 3 es la única imagen en la que aparece la figura humana de toda la versión del Reglamento para el control nacional de Fraccionamientos y Urbanizaciones de $1983 .{ }^{4}$ En ella, las personas muestran un mínimo de movimiento, se encuentran dentro del espacio que les corresponde (la acera), no realizan actividades "inadecuadas" (futbol callejero por ejemplo). La persona y la vegetación son solo ornamentaciones en la imagen, la cual lo que busca es mostrar los valores funcionales y cuantitativos del espacio, como la longitud de los elementos ${ }^{5}$. 
Lo anterior, y el estudio documental realizado, muestra que lo vivido por las personas en la ciudad y la forma como el espacio se relaciona con ellas es prácticamente irrelevante para urbanizadores y planificadores del territorio. Solamente podría tener importancia si mantiene estricta relación con la propiedad privada y su ordenamiento funcional en el espacio.

\section{La jerarquía como forma de ordenar}

Pero la propiedad por sí sola no da un sistema de orden que permita organizar racionalmente el espacio; es aquí donde aparece la jerarquía, la cual se define, en los documentos estudiados, desde razones cuantitativas en su mayoría (principalmente densidad, cantidad de población y dimensiones). Se encontró un tipo de jerarquía progresiva en la que el rango más alto contiene al segundo y el segundo contiene al tercero. Por ejemplo, la jerarquía mostrada por las Normas Mínimas de Diseño Geométrico en Urbanizaciones (INVU, 1979b), para determinar la necesidad de facilidades comunes:

1. Grupo familiar o barrio: Constituido por 1000 personas, puede tener un jardín de niños (kindergarden).

2. Centro de Unidad Vecinal: Constituido por 5000 personas, puede tener una escuela primaria.

3. Centro de Sector Residencial: Constituido por 20000 habitantes, puede tener un colegio de enseñanza media.

Esta centralización, que está presente en otras jerarquías definidas en los documentos estudiados, tiende a generar la dualidad centro/periferia, dando siempre mayores beneficios al centro. Además, es importante notar que lo periférico y de menor rango siempre se relaciona con lo local, vecinal o rural (INVU; 1979b, 1973, 1984).

Por otro lado, en el caso de los lotes, la jerarquización insinúa el rango de recurso económico que las personas deben tener para habitar allí. El mayor ejemplo de esto es que al caracterizar zonas a urbanizar según densidad de población y dimensiones de lotes, en las Normas mínimas de diseño geométrico en urbanizaciones, se le asigna una categoría completamente aparte a la "vivienda popular" (INVU, 1979b, p. 7), a la cual se le asignan "normas especiales" que aumentan la densidad y disminuyen el tamaño de los lotes. Asimismo, se da la categorización de las vías, la cual tiene implicaciones mayoritariamente geométricas, como se puede observar en la tabla 1.

$6 \quad$ Es importante recordar que todo esto sigue estrechamente relacionado con la propiedad privada. Es sabido que la propiedad siempre ha sido un parámetro para categorizar y ordenar la estructura social. Blomley, 2003.
Esta jerarquización geométrica está vinculada con las zonas segmentadas por rango económico, con las vías de mayor rango y las relaciones de centro/periferia. De todas estas relaciones se obtiene un sistema de orden, jerarquizado y fragmentado ${ }^{6}$. Como se mostrará, ejemplificándolo por medio del caso de Hatillo 8, son estos los principios de diseño mostrados por el INVU durante el periodo de estudio para lograr un ordenamiento "eficiente" del espacio, lo que los convierte en fundamentos representativos de la producción del espacio de Hatillo y de Costa Rica.

\begin{tabular}{l|l|l}
\hline \multicolumn{2}{c}{ Tabla 1: Clasificación de vías } \\
\hline Nombre & Derecho de vía $(\mathrm{m})$ & Pavimento $(\mathrm{m})$ \\
\hline Primaria & 24 & 19 \\
\hline Secundaria I & 19 & 13 \\
\hline Secundaria II & 17 & 11 \\
\hline Locales & 14 & 9 \\
\hline En U o de continuidad limitada & 11 & 7 \\
\hline Sin salida & 11 & 7 \\
\hline Alameda & 11 & Sin pavimento
\end{tabular}


Como se puede observar en la figura 4, el espacio que estaba dispuesto para ubicar Hatillo 8 fue delimitado por dos vías primarias en sentido longitudinal que lo conectan con el resto de los Hatillos; luego, estas vías son unidas por algunas vías secundarias en sentido transversal. Tanto las primarias como las secundarias son de uso vehicular. Son únicamente las vías estrictamente necesarias para lograr el resto del ordenamiento.

Una vez asegurado el acceso a Hatillo 8, y una mínima circulación vehicular dentro de él, se disponen en el resto del espacio vías del menor rango posible para acceder a los lotes (los cuales, como se ha mencionado, son los lotes de menor tamaño entre todos los Hatillos). Asimismo, los lotes están jerarquizados en correspondencia, ya que la mayoría de los que poseen un área mayor se encuentran locªlizados en las vías primarias o son esquineros. Es así como los fundamentos conceptuales de jerarquía que rigen los documentos estudiados se reflejan en el espacio.

Los principios de diseño mostrados hasta ahora, vistos a una escala regional, son causa de la fragmentación social y marginalidad de los barrios periféricos de la capital, promovidos desde las instituciones estatales durante la segunda mitad del siglo XX (Carvajal y Vargas, 1983; Alvarenga, 2009). Es decir, que se está hablando aquí de un proceso que perpetúa las desigualdades sociales y las plasma en el espacio, tema que será profundizado en el siguiente apartado.

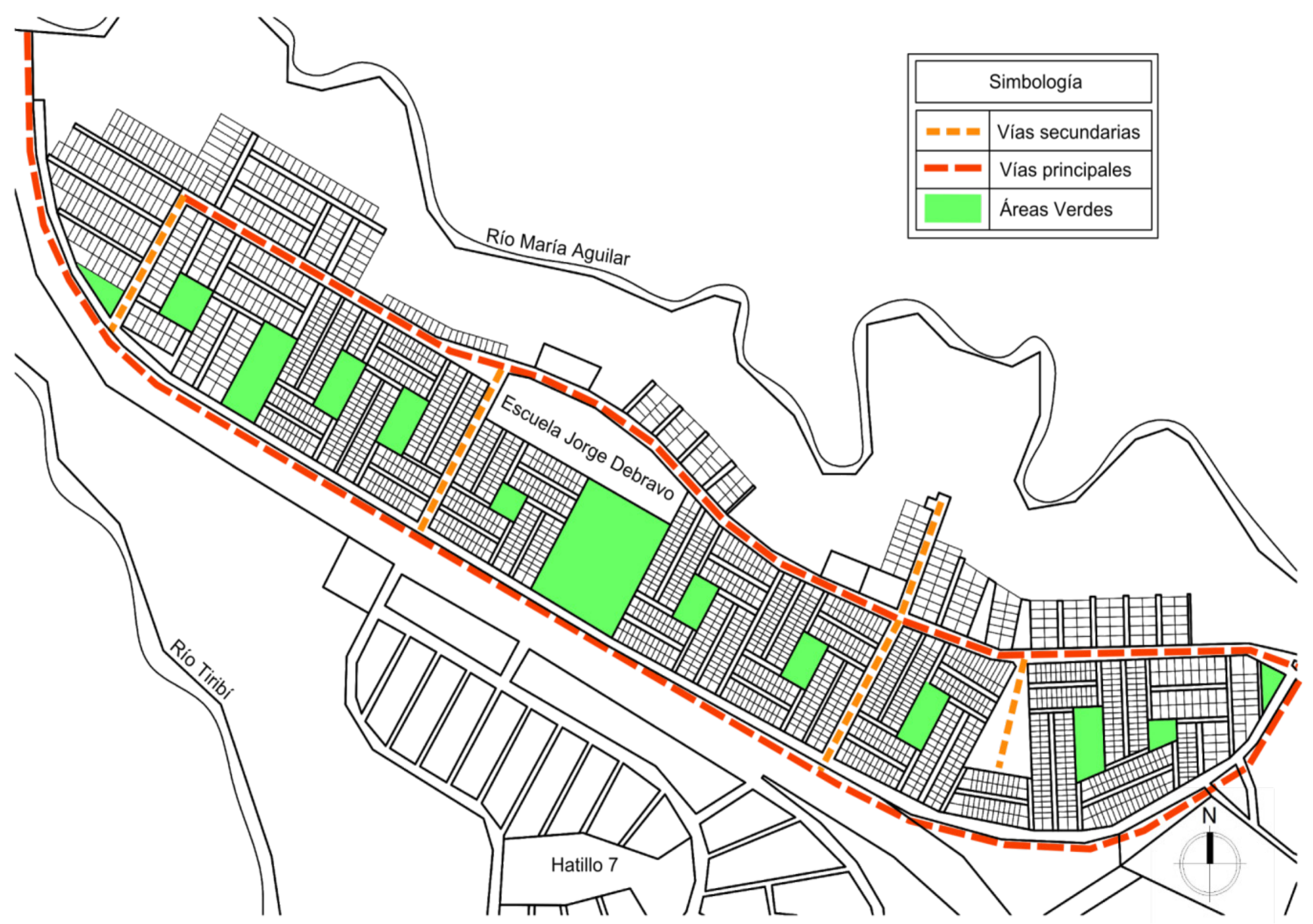

A

Figura 4. Mapa Hatillo 8. Elaboración propia con base en Barrios, servicios públicos y comunales del distrito Hatillo, Municipalidad de San José.

\section{Para el que tiene menos, lo "mínimo"}

A la vivienda popular no sólo se le destina a tener mayor densidad, sino que todas las normas ordinarias de fraccionamiento y urbanizaciones se reducen a las "normas mínimas" o en algunos casos a menos de lo que se indica como "mínimo". En el artículo 27 de una de las versiones del Reglamento para el control nacional de fraccionamientos y urbanizaciones del INVU, se permite la reducción de las "normas técnicas ordinarias" a "normas mínimas" cuando el proyecto es destinado a "vivienda popular de bajo costo" (1973, p. 9). La intención de esta reducción se explica en el artículo 29 del mismo reglamento que dice: "La aplicación de las normas mínimas ha de corresponder en forma integral al interés social de reducir, en lo posible, el costo de la vivienda popular destinada a familias de bajos ingresos" (p. 9). 
La reducción de las normas no está en función de los habitantes de dichos proyectos de vivienda, sino que está presuponiendo la necesidad de que los costos para la institución estatal o la empresa privada tienen que ser bajos para que la solución de vivienda sea también de bajo costo. Vuelven a mostrarse los conceptos económicos y de propiedad privada preestablecidos como determinantes de las normas. Se asume que la vivienda es una mercancía que debe ser adquirida mediante la transacción de capital, y que el gobierno y la empresa privada no deben tener pérdidas, y en el segundo caso, además, debe tener ganancias. Las leyes asumen el objetivo de reducir el costo económico de producción.

Por ejemplo, se dice explícitamente en las Normas Mínimas de Diseño Geométrico en Urbanizaciones (INVU, 1979b) que para proyectos de "interés social" se permite que las calles no se pavimenten y se conviertan en alamedas. Simultáneamente, en el mismo documento se indica que para los desarrollos de vivienda social se permitirán vías terciarias con derecho de vía de $7 \mathrm{~m}$ y para acceso únicamente peatonal hasta de tan solo $6 \mathrm{~m}$.

Por tanto, las alamedas no nacen de una visión a favor de disminuir el uso de vehículos motorizados, bastante aceptada en la actualidad. En cambio, la ausencia de vehículos es, desde lo que muestran los documentos, solamente una característica de la condición económica baja de los habitantes de los proyectos de interés social, la cual permite la disminución de los costos al dejar mayor cantidad de área sin pavimentar.

Así, la alameda no es la incorporación en el diseño de características sociales de los sectores poblacionales que habitarán el proyecto de vivienda popular, sino que las características socio-económicas de los habitantes aparecen como determinantes de lo físico, desde el punto de vista del orden oficial, siempre y cuando representen una disminución en el costo de inversión para los propietarios que inician la urbanización.

A partir de lo anterior se explica, por ejemplo, por qué se recomienda que las aceras se hagan de tan solo un metro de ancho (ver figura 5). El único argumento, dentro de la lógica mostrada por el INVU, que justifica una configuración de este tipo es disminuir los costos para el inversor. Lo anterior provoca condiciones físicas que no buscan la apropiación de ningún tipo por parte de los habitantes de las alamedas. Son espacios concebidos única y exclusivamente para el tránsito peatonal; cualquier uso fuera de esto va en contra de lo que el espacio físico sugiere y por tanto implica una disputa.

Entonces, la alameda se empieza a vincular con sectores de escasos recursos económicos y se vuelve herramienta de los urbanizadores para, según los fundamentos descritos hasta ahora, optimizar el ordenamiento de las viviendas en el espacio, como es posible observar en la figura 4. Esto nace como legislación en el INVU. Hatillo es de los principales lugares en que se pone en práctica y tiene implicaciones nacionales. Sin embargo, no solo el poder oficial asigna usos y atribuciones simbólicas al espacio; las personas que habitan el espacio se apropian de él. A continuación se describirán algunos apuntes al respecto.

\section{Las apropiaciones}

A pesar de lo explicado en los apartados anteriores, aunque no era lo común, se sabe que existieron huertas en las alamedas y que provocaban intercambios de productos entre vecinos. Por ejemplo, Gerardo y Verónica, una pareja que vive en Hatillo 8 desde la construcción de la casa que aún habitan, recuerdan con orgullo la huerta que tenían al frente de su casa, en la alameda. En ella se podían apreciar rosales, naranjas, romero, hierbabuena y rabo de gato; este último para la cerca que construyeron con el fin de delimitar el sector de la alameda que utilizaron.

Esta forma de apropiarse del espacio sin duda tiene relación con el hecho que se ha podido constatar en diferentes entrevistas y conversaciones informales: al entregar la vivienda a una familia, los funcionarios del INVU indicaban a la nueva habitante que la mitad de la alameda que se encontraba al frente del lote asignado le corresponde para su cuidado, prolongando simbólicamente la propiedad. Además, para el caso de Hatillo, una de las principales razones por las que las personas migraron a esta ciudadela fue por la oportunidad de tener casa propia (Hernández, Herrera y Vargas, 1984). Esto 
Figura 5. Alameda típica. Extraída de Normas Mínimas de Diseño Geométrico en Urbanizaciones. INVU, 1979b.
Figura 6. Al lado derecho de la fotografía se observa la alameda intervenida de diferentes formas por cada familia, incluyendo un parqueo para motocicletas. Fotografía propia, noviembre del 2014. recuerda que la importancia de la propiedad en la sociedad supera el espacio de Hatillo y la legislación del INVU, por lo que es de suponer que las personas que llegaron a vivir en Hatillo ya habían interactuado con ciertas representaciones y vivencias relacionadas con la importancia de la propiedad individual.

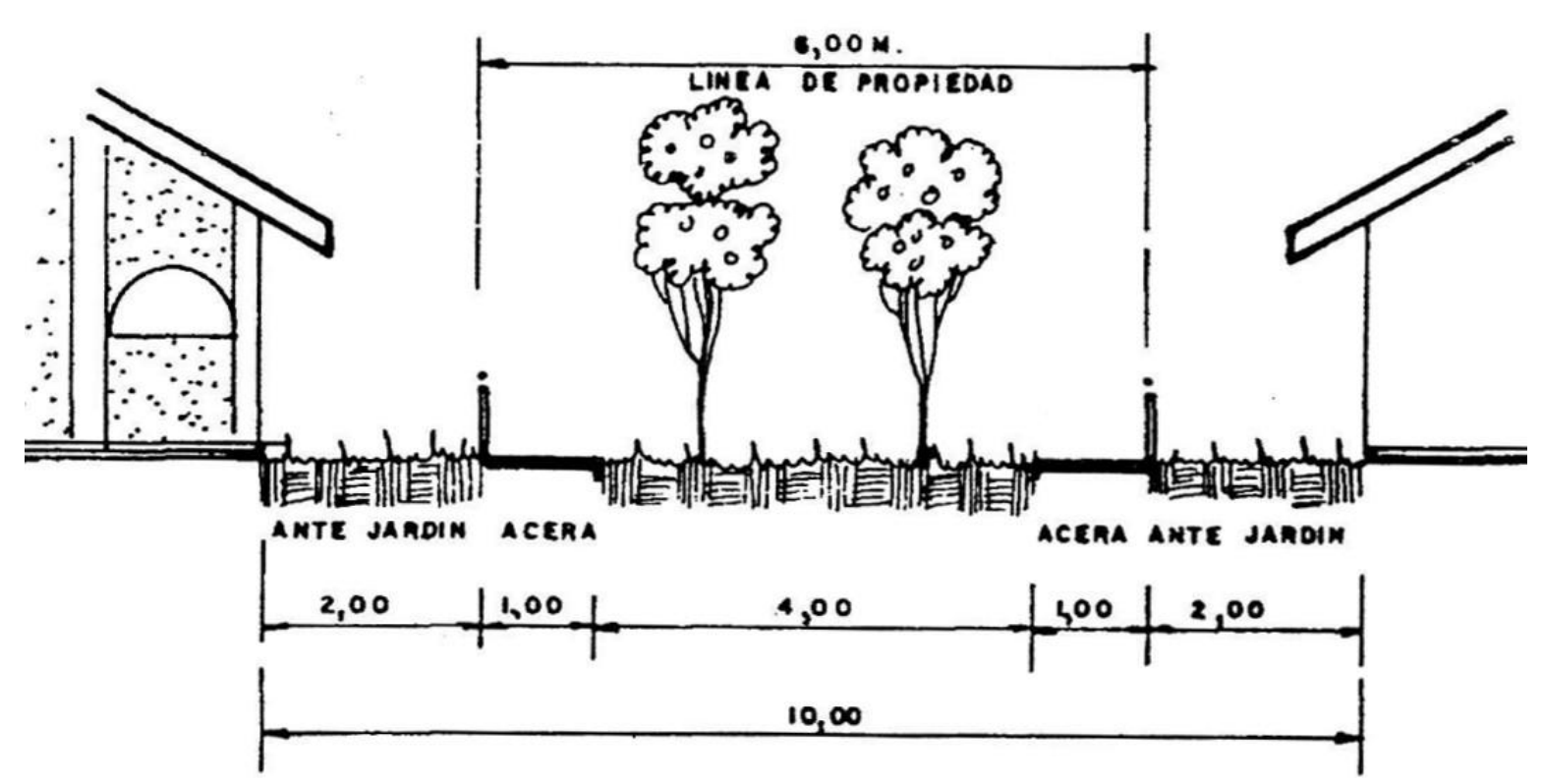

Varios casos, constatados en entrevistas o por la observación en sitio, muestran que las alamedas funcionaron siempre interpretadas como extensiones del espacio que se consideraba propio; que esta apropiación individual de un espacio legalmente público se realizó asumiendo que la institución estatal lo validaba; y que en muchos casos se decidió mantener el espacio de la alameda sin modificaciones, sin cerca y con un aspecto descuidado. En Hatillo 8 siguen existiendo muchas cercas como elementos físicos construidos por los habitantes y muestran claramente cómo la apropiación tuvo implicaciones materiales contundentes.

Por ejemplo, se modificaron los elementos urbanos que se encuentran al nivel del suelo o cercanos a él para ajustarlos a los usos que cada familia necesitaba, lo cual incluye espacios para estar, diversas formas de crear jardines y espacios de parqueo para los medios de transporte que cupieran en el reducido espacio que le correspondía a cada familia (ver figura 6).
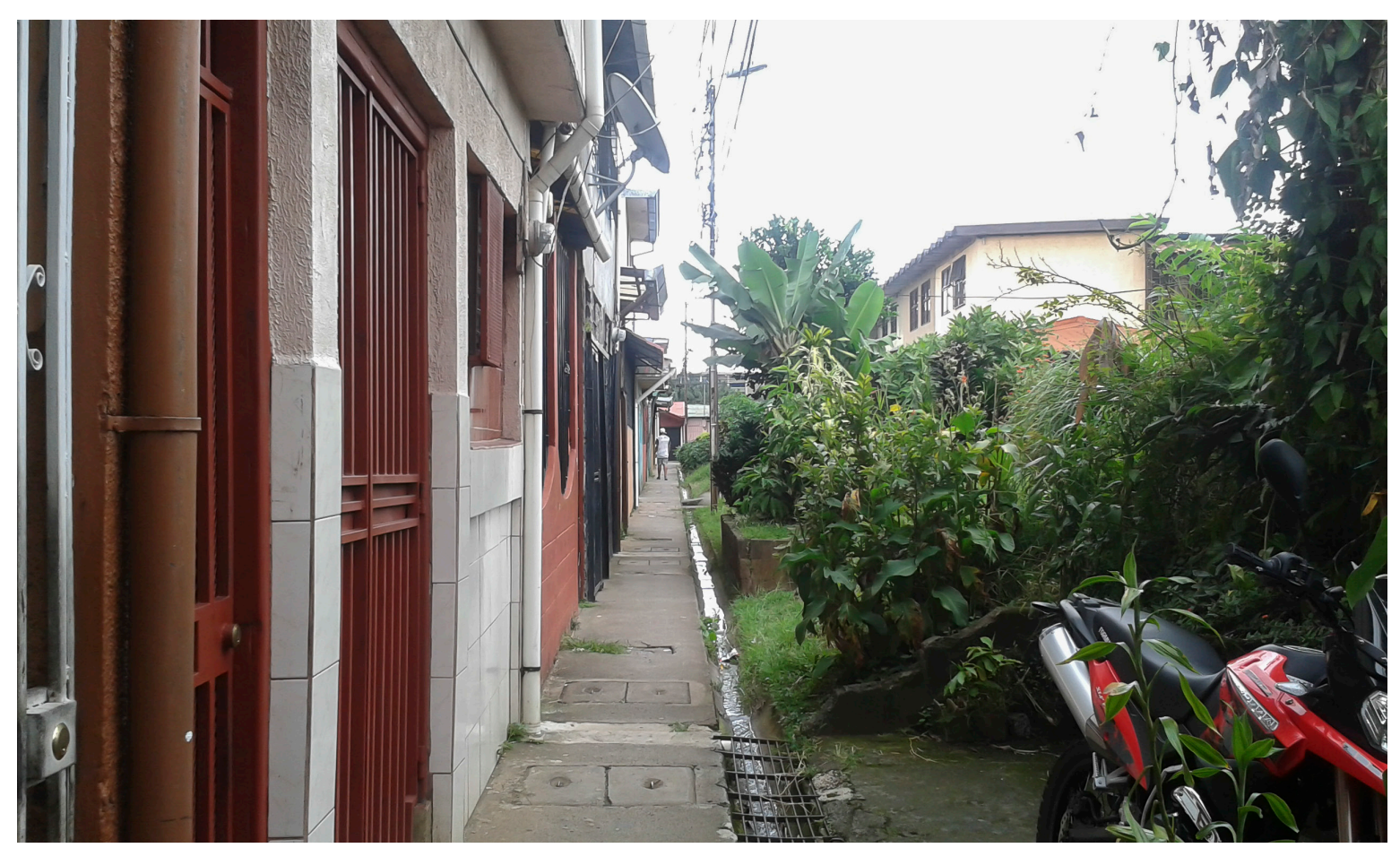

Dichas apropiaciones se realizaron en una vía de tránsito que, como se ha mencionado, nunca fue pensada para huertas urbanas, jardines o parqueos de motocicletas (INVU, 1979b; 1983). Esto evidencia que se amplía o cuestiona el uso oficial del espacio público, pero esto se hace una vez que dicho espacio es legitimado como extensión de la propiedad privada. Por tanto, esta apropiación, en sus acciones y vínculos simbólicos, es muy similar a la realizada por cada familia en la casa que se les asignaba. 


\section{La alameda: a modo de conclusión}

Entonces, jurídicamente la alameda nace marginada a construirse en los barrios de clase socio-económica más baja, y el motivo que lleva a su existencia es lograr disminuir la inversión realizada por el desarrollador, ya sea privado o estatal. Por lo tanto, la alameda, desde el orden oficial, cumple la función de ubicar una gran cantidad de población en un menor espacio y a un menor costo económico.

En cuanto a las apropiaciones, se vio que el discurso hegemónico con respecto a la propiedad permea hasta llegar al imaginario de que a cada familia le corresponde un sector de la alameda, como simple extensión de su propiedad privada. El uso colectivo de estos espacios, más allá de la rutinaria y ya predispuesta acción de transitar, se dio esporádicamente por los juegos de niños y niñas, en especial décadas atrás, como se pudo constatar en las entrevistas y conversaciones. ${ }^{7}$

Las alamedas de Hatillo 8 están claramente compuestas por el área verde $(3,20 \mathrm{~m}$ de ancho), la acera ( $1 \mathrm{~m}$ de ancho) y el caño (40 $\mathrm{cm}$ de ancho) que divide la acera y el área verde, al igual que lo estipulado posteriormente en las normas (ver figura 5). En los reglamentos se permiten diferentes formas de disponer estos componentes, pero nunca se agrega ni resta ninguno de ellos (INVU, 1979b). La acera, un cinturón de concreto continuo, fue diseñada únicamente para transitar de forma individual; el caño cumple la función de desalojar las aguas llovidas tanto de los techos de las casas como de la alameda; y el área verde es una capa de tierra sin pavimentar.

Ya que se pretende que la alameda cumpla una finalidad estrictamente funcional y está relacionada con las clases bajas, sus dimensiones regularmente son las mínimas según los reglamentos, y se mantienen iguales durante toda su longitud. Esto provoca un espacio realmente estrecho, incómodo sensorialmente, donde la línea de propiedad de las viviendas está al lado de aceras muy pequeñas, provocando que la dimensión de la acera se perciba aún menor (ver figura 6). ${ }^{8}$

Lo anterior es importante ya que es un factor más para que las apropiaciones colectivas de este espacio sean menos frecuentes. A partir de la información recolectada en las entrevistas, las conversaciones informales, y la observación de la situación actual no se sabe de ningún caso en Hatillo 8 en que una alameda haya sido intervenida colectivamente, con excepción del aproximadamente $16 \%$ de las alamedas que en la actualidad están pavimentadas en Hatillo 8 para el uso vehicular ${ }^{9}$. Sin embargo, esta intervención fue motivada y ejecutada directamente desde la Municipalidad.

A continuación, se puntualizan las características físicas relevantes dentro de las argumentaciones de este trabajo y se muestra una síntesis comparativa en la tabla 2:

$7 \quad$ Este dato no es menor; lastimosamente, no fue posible profundizar en él a lo largo de la investigación. Queda como deuda en este trabajo desarrollar las contradicciones y disputas que nacen al confrontar los discursos oficiales con las perspectivas de las poblaciones históricamente marginadas, como lo son las mujeres, la niñez, las juventudes, las personas migrantes, etc.

$8 \quad$ Esto se constata tanto por las observaciones del autor como por las entrevistas y conversaciones.

$9 \quad$ Dato recopilado en sitio por el autor.

10 Sobre el "urbanismo a ras del suelo" y otros ejemplos sobre lo determinante que es en cuanto a definir usos, propiedades y jerarquías se recomienda revisar algunos trabajos recopilados en Architecture after Revolution (Hilal, et al., 2013).
1. Los materiales (tierra o concreto) y elementos arquitectónicos que se encuentran cerca del nivel del suelo (cercas o vegetación) ${ }^{10}$ son determinantes para asignar, dividir y distinguir las diferencias de propiedad y usos "adecuados". Por ejemplo, el concreto promueve el tránsito peatonal y la tierra la siembra. Estos usos, en la mayoría de los casos, se respetan por los habitantes de Hatillo 8 hasta la actualidad.

2. La escala del espacio y su homogeneidad en cuanto a las dimensiones no ayuda a la existencia de nuevas formas de apropiación. Debido a su baja jerarquía se reduce la inversión económica y por tanto el tamaño de los componentes.

Lo descrito hasta ahora puede, por lo menos, permitir sospechar que la importancia de la propiedad privada, promovida desde el orden oficial, influyó a los habitantes en su forma de apropiarse de las alamedas, individualizada por familias. También, que los planificadores utilizaron principios de diseño, que quedaron plasmados en los textos del INVU estudiados en esta investigación, vinculados más con la utilidad de la propiedad privada y la disminución de costos económicos que con las formas cotidianas de vivir el espacio. Por tanto, en este punto, es posible plantear que si otras fueran las relaciones de poder y si otros fueran los regímenes de propiedad que influyen el espacio, sin duda otras serían las características físicas de los elementos urbanos, quizás más propicias para apropiaciones diversas y cambiantes, sin que la clase social a la cual se pertenece determine dichas posibilidades de apropiación. 
Tabla 2. La Alameda: Formas de apropiación en Hatillo 8. Elaboración propia.
Estas características evidenciadas en la producción de la alameda en Hatillo 8 permiten afirmar que imposiciones físicas tan claras y específicas como las que se han descrito no se pueden modificar en general simplemente con el trabajo y buena intención de profesionales en diseño y planificación, ya que su génesis proviene de conceptos y condiciones arraigadas profundamente en la forma en que se concibe el espacio, como lo son la propiedad privada y las relaciones jerárquicas en la sociedad. Simultáneamente, cualquier proyecto que pretenda modificar estos principios debe incluir un cambio radical en cuanto al espacio y la arquitectura. El compromiso político que esta proposición exige a los profesionales que traten el diseño urbano y arquitectónico para dejar de ser simplemente ejecutores de los mandatos de los sectores dominantes es un imperativo que no debería ser ignorado.

\begin{tabular}{|c|c|c|}
\hline & Acción-transformación & Simbólico \\
\hline Orden oficial & $\begin{array}{l}\text { Sus transformaciones físicas } \\
\text { fueron guiadas hacia la menor } \\
\text { inversión económica. }\end{array}$ & $\begin{array}{l}\text { Ya que posee la menor jerarquía } \\
\text { geométrica y simbólica se encuentra } \\
\text { relacionada con los sectores de menores } \\
\text { recursos económicos. }\end{array}$ \\
\hline $\begin{array}{l}\text { Orden } \\
\text { vernacular }\end{array}$ & $\begin{array}{l}\text { Se modifica con autonomía, } \\
\text { siempre y cuando se haga } \\
\text { dentro del marco indicado por el } \\
\text { orden oficial. }\end{array}$ & $\begin{array}{l}\text { Se comprende como extensión de la } \\
\text { propiedad privada. }\end{array}$ \\
\hline $\begin{array}{l}\text { Estructura } \\
\text { urbana }\end{array}$ & $\begin{array}{l}\text { La arquitectura cercana al nivel } \\
\text { del suelo es fundamental para } \\
\text { indicar la propiedad y los usos. }\end{array}$ & $\begin{array}{l}\text { No posee prácticamente nada que estimule } \\
\text { o indique la posibilidad de apropiaciones } \\
\text { colectivas. }\end{array}$ \\
\hline
\end{tabular}

\section{Referencias bibliográficas}

Alvarenga, P. (2009). De vecinos a ciudadanos. Movimientos comunales y luchas cívicas en la historia contemporánea de Costa Rica. San José: Editorial UCR y Editorial de la Universidad Nacional.

Araya, D. (2016). La estructura urbana: Análisis de la producción del espacio en Hatillo 8 (1973-1984) (Tesis de licenciatura). Universidad de Costa Rica, Costa Rica.

Ares, P. y Rister, J. (2013). Manual de mapeo colectivo: recursos cartográficos críticos para procesos territoriales de creación colaborativa. Buenos Aires. Recuperado el 6 de marzo, 2015, de http://www.iconoclasistas.net/post/manual-de-mapeocolectivo-en-pdf/

Blomley, N. (2003). Law, Property, and the Geography of Violence: The Frontier, the Survey, and the Grid. Annals of the Association of American Geographers, 93(1), $121-141$

Calvo, S. (1982). Recreación de la "Ciudad Satélite de Hatillo" e identidad de sus habitantes (Tesis de licenciatura). Universidad de Costa Rica, Costa Rica.

Carvajal, G. y Vargas, J. (1983). Proceso de metropolización en el valle central de Costa Rica: 1940 a 1980. Informe Final. San José: CSUCA.

Esquivel, F. y Solís, M. (1980). Las perspectivas del reformismo en Costa Rica. San José: Departamento Ecuménico de Investigaciones y Editorial Universitaria Centroamericana.

Federici, S. (2010). Calibán y la bruja. Mujeres, cuerpo y acumulación originaria. Madrid: Traficantes de sueños.

Flyvbjerg, B. (2004). Cinco malentendidos acerca de la investigación mediante los estudios de caso. Revista Reis, 106(4), pp. 33-62.

Harvey, D. (1990). La condición de la posmodernidad. Investigación sobre los orígenes del cambio cultural. Buenos Aires: Amorrortu editores S.A. 
Hernández, C., Herrera, M. y Vargas, F. (1984). Expresiones Arquitectónicas y Culturales en la Ciudad Satélite de Hatillo (Tesis de licenciatura). Universidad de Costa Rica, Costa Rica.

Hernández, R., Fernández, C. y Baptista, P. (2006). Metodología de investigación. México D.F.: Mc Graw Hill.

Hilal, S., Petti, A. y Weizman, E. (2013). Architecture after Revolution. Berlín: Sternberg Press.

Hourtart, F. (2000). Análisis estructural de textos. Método propuesto por J. Gritti. En R. M. Pochet Coronado. (Comp.), Discurso y análisis social. Métodos cualitativos y técnicas de análisis (pp. 135-172). San José: Editorial de la Universidad de Costa Rica.

INVU. (1973). Reglamento para el control nacional de fraccionamiento y urbanizaciones. San José: Imprenta Nacional.

INVU. (1974). Organización, objetivos, el problema de vivienda, realizaciones, aspectos financieros, planes de vivienda, planeamiento físico. Costa Rica: Taller de publicaciones INVU

INVU. (1979a). Hatillo 79. San José: Departamento de urbanismo.

INVU. (1979b). Normas mínimas de diseño geométrico en urbanizaciones. San José: Departamento de urbanismo.

INVU. (1982). Reglamento para el control nacional de fraccionamiento y urbanizaciones. San José: Taller de publicaciones del INVU.

INVU. (1983). Reglamento para el control nacional de fraccionamiento y urbanizaciones. San José: Taller de publicaciones del INVU.

INVU. (1984). Glosario de términos de urbanismo y construcción. San José: Dirección de urbanismo.

Kropf, K. (2009). Aspects of urban form. Urban Morphology, 13(2), 105-120.

Lefebvre, H. (1972). La Revolución Urbana. Madrid: Alianza Editorial S.A.

Lefebvre, H. (1974/2013). La producción del espacio. Madrid: Capitán Swing Libros, S. L.

Márquez, R. (2015). La propiedad como hecho social. Una contribución etnográfica a la crítica del economicismo. Revista de Antropología Social, 24, 83-104.

Merino, R. (2014). Descolonizando los derechos de propiedad. Derechos indígenas comunales y el paradigma de la propiedad privada. Boletín Mexicano de Derecho Comparado, XLVII(141), 935-964. Recuperado de http://www.redalyc.org/articulo. oa?id=42732620004

Núñez, A. (2011). Formas socioterritoriales de apropiación del habitar y derecho al espacio diferencial. Territorios, 24, 165-191. Recuperado de http://www.redalyc. org/articulo.oa?id=35718640007

Pol, E. y Vidal, T. (2005). La apropiación del espacio: una propuesta teórica para comprender la vinculación entre las personas y los lugares. Anuario de Psicología, 36(3), 281-297

Scott, J. (1998). Seeing Like a State: How Certain Schemes to Improve the Human Condition Have Failed. Estados Unidos: Yale Agrarian Studies.

Scott, J. (2012). Two cheers for anarchism: Six Easy Pieces on Autonomy, Dignity, and Meaningful Work and Play. Estado Unidos: Princeton University Press.

Solís, M. A. (1992). Costa Rica: ¿Reformismo socialdemócrata o liberal? Costa Rica: FLACSO.

Somer, K. (2007). The Functional City. The CIAM and Cornelis van Eesteren, 19281960. Rotterdam: NAi Publishers, EFL Foundation.

Tonon, G. (2011). La utilización del método comparativo en estudios cualitativos en ciencias políticas y ciencias sociales: Diseño y desarrollo de una tesis doctoral. Revista Kairos de Temas Sociales, 15(27). Recuperado de www.revistakairos.org 